\title{
Engineering Controlled Low Strength Materials Using Scrap Tire Rubber
}

\author{
Tammie Cheung ${ }^{1}$; Daniel C. Jansen², A.M. ASCE; James L. Hanson ${ }^{3}$, M. ASCE, P.E. \\ ${ }^{1}$ Analyst, Kimley-Horn and Associates, Inc., 517 Fourth Ave., Suite 301, San Diego, CA, 92101, \\ Tammie.Cheung@kimley-horn.com \\ 2 Associate Professor, Dept. of Civil and Env. Eng., Cal Poly State University, San Luis Obispo, CA \\ 93407-0353,djansen@calpoly.edu \\ ${ }^{3}$ Associate Professor, Dept. of Civil and Env. Eng., Cal Poly State University, San Luis Obispo, CA \\ 93407-0353,jahanson@calpoly.edu
}

\begin{abstract}
An investigation was conducted to determine the influence of recycled scrap tire rubber on the engineering properties of controlled low strength material (CLSM). With control over the ultimate compressive strength of CLSMs being key for applications such as backfilling utility trenches where re-excavation is often necessary, incorporation of scrap tire rubber into the CLSM mixture is a viable way to limit the ultimate strength. The work presented includes the results of 27 batches of CLSM, 20 of which included scrap tire rubber. The variables included: cement content, fly ash content, and fractional replacement of sand with scrap tire rubber. Results show that incorporation of scrap tire rubber into CLSM mixtures can be an effective way to limit term strength gain although it adds its own complexity.
\end{abstract}

\section{INTRODUCTION}

Controlled Low-Strength Material (CLSM), also known as flowable fill, is defined by the American Concrete Institute as a "material that results in a compressive strength of $8.3 \mathrm{MPa}$ (1200 psi) or less." However, CLSM is often designed with future excavation in mind, which should have an unconfined compressive strength UCS) of 2.1 MPa (300 psi) or less (ACI Committee 229 1999). While these strengths seem low, an UCS of 0.3 to $0.7 \mathrm{MPa}$ (50 to $100 \mathrm{psi}$ ) is equivalent to a well compacted fill (ACI Committee 229 1999). The most common use for CLSM is as backfill material; other uses include: foundation supports, pavement bases, sub-base, and subgrades. Flowable fill is mixed and placed similarly to fluid concrete and ideal for confined spaces where mechanically compacting earthen fill is difficult or costly. CLSM mixtures are self-compacting, cementitious materials typically consisting of water, portland cement, fly ash, and fine aggregates.

Typically, fine aggregate is used with small amounts of portland cement and large 
volumes of fly ash and water. The large water content provides the fluidity of the CLSM, and fly ash serves as a fine material preventing segregation and excessive bleeding without giving the CLSM too high a long term strength. A higher cement content could be used to achieve the desired fluidity, or flow, without bleeding or segregation; however, the long term strength would then be excessive, especially for excavatable flowable fills. Fine aggregate is a major component of flowable fill often accounting for two-thirds by weight (Pierce and Blackwell 2003). Recycled materials that are readily available should be considered as alternative aggregate sources in CLSM. Materials such scrap tires, foundry sand, cement kiln dust, and combined fuel ash are few examples of industrial by-products that can be used as a substitute for fine aggregate in CLSM (Pierce et al. 2003, Tikalsky et al. 1998, Tikalsky et al. 2000).

The United States produces nearly 300 million scrap tires per year (Rubber Manufacturers Association 2006). Of these scrap tires, 14\% are landfilled or dumped (legally or illegally) in stockpiles. The largest portions of scrap tires being used are burned for tire derived fuel (52\%), civil engineering applications (16\%), and ground rubber (12\%) (Rubber Manufacturers Association 2006).

Finely processed scrap tire, termed crumb rubber, was used successfully in flowable fill in research conducted by Pierce and Blackwell (2003); they demonstrated crumb rubber can be used in flowable fill for applications such as bridge abutment fills, trench fills and foundation support fills. However, research including other forms of scrap tire in CLSM has not been reported in literature. A form of readily available scrap tire is rubber buffings. Rubber buffings are produced from retreading tires or scrap tires destined for landfills. The tires are "buffed" by equipment known as retread buffers. Retread buffers remove old tread from tires so new treads can be applied, or they remove extra rubber from scrap tires prior to landfilling. Rubber buffings are elongated particles which are coarser than crumb rubber particles. Scrap tire rubber buffings have been used as cushioning under playground equipment but need to be stabilized to prevent migration by wind or water forces.

\section{MATERIALS}

\section{Cementitious Materials}

A Type II/V portland cement was used throughout the testing program; Type II/V is very common in California and is used to improve resistance to sulfate attack. The specific gravity of the cement was assumed to be 3.15 .

The fly ash used throughout the investigation was a Class F fly ash with strength activity indices, as determined per ASTM C311, of $76 \%$ and $81 \%$ at 7 and 28 days, respectively. The specific gravity of the fly ash was 2.37 .

\section{Sand (Fine Aggregate)}

The absorption and specific gravity of the sand were measured to be $1.7 \%$ and 2.55 , respectively. The sand used in this investigation satisfied the gradation requirements of ASTM C33, although sand used in flowable fill is not generally required to satisfy ASTM requirements. The fineness modulus was determined to be 2.53 . When used in the CLSM, the sand was taken directly from the stockpile; samples of the sand were oven dried to determine its moisture content. 


\section{Scrap Tire}

The scrap tire used was in the form of tire buffings as shown in Figure 1. The scrap tire buffings were clean rubber, containing no steel belts or fibers. Sieve analyses were performed on the scrap tire; sizes ranged from $0.075 \mathrm{~mm}$ to $4.75 \mathrm{~mm}$ with more than $70 \%$ by weight between the \#8 $(2.36 \mathrm{~mm})$ and \#30 $(0.600 \mathrm{~mm})$ sieves. The gradation did not meet the requirements of ASTM C33 for fine aggregates. Sieve analyses do not properly represent the particle sizes due to the highly elongated nature of tire buffings. The scrap tire buffings contained little moisture and were assumed to have zero absorption. The specific gravity was determined to be 1.16.

\section{PROCEDURES}

\section{Mixing and Testing for Fresh Properties}

The proportions for the CLSM mixtures were designed for target cement contents ranging from 30 to $180 \mathrm{~kg} / \mathrm{m}^{3}$, fly ash contents between 0 and $360 \mathrm{~kg} / \mathrm{m}^{3}$, and weight ratios of scrap tire to sand between 0 and 1.0. The Sample I.D. given in Table 1 reflects the target design content for the mixture (for example, sample 120/180/0.25 was designed to have a cement content of $120 \mathrm{~kg} / \mathrm{m}^{3}$, a fly ash content of $180 \mathrm{~kg} / \mathrm{m}^{3}$ and a ratio of scrap tire to sand of 0.25 by weight). When scrap tire was used, an equivalent volume of sand was replaced with scrap tire. The batches were mixed using a laboratory drum-style mixer. Flow, a measure of workability, was measured as the diameter to which the CLSM mixture spread, starting in a $75 \mathrm{~mm} \times 150 \mathrm{~mm}$ open ended cylinder, subsequent to the cylinder being lifted, see Figure 2; the procedure was in general accordance with ASTM D6103. The water content was established to provide suitable flow; the water content of each batch was increased until a flow of 200 to $300 \mathrm{~mm}$ was reached or excessive clear water leaked from the bottom end of the $75 \times 150 \mathrm{~mm}$ cylinder before being lifted. The flow for each batch is provided in Table 1. The unit weight and air content of the CLSM were measured based on the procedures provided in ASTM D6023. The mixture proportions listed in Table 1 were adjusted for the actual moisture content of the sand (so it is in the saturated surface dry state), amount of water used, and unit weight.

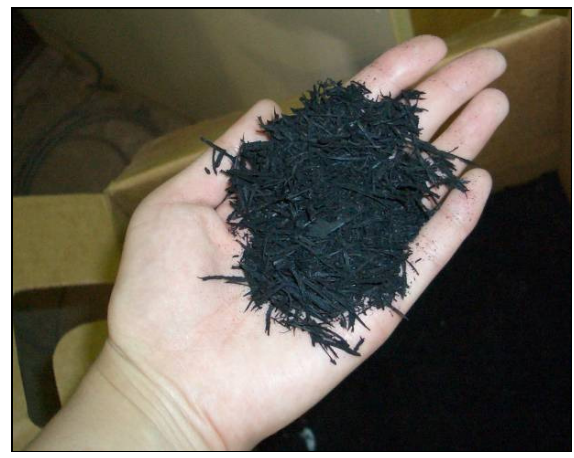

FIG. 1. Scrap Tire Rubber Buffings

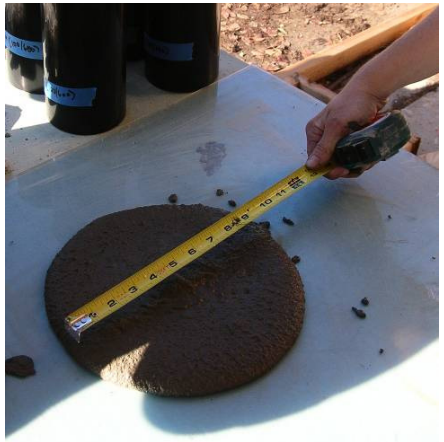

FIG. 2. Testing for Flow 
Table 1. CLSM Mixture Proportions and Properties

\begin{tabular}{|c|c|c|c|c|c|c|c|c|c|}
\hline \multirow[b]{2}{*}{$\begin{array}{c}\text { Sample } \\
\text { I.D.* }\end{array}$} & \multicolumn{5}{|c|}{ Mixture Proportions } & \multirow[b]{2}{*}{$\begin{array}{l}\text { Flow } \\
(\mathrm{mm})\end{array}$} & \multirow[b]{2}{*}{$\mathrm{c} / \mathrm{cm} \dagger$} & \multirow[b]{2}{*}{$\mathrm{w} / \mathrm{cm}^{\ddagger}$} & \multirow[b]{2}{*}{$\begin{array}{c}28 \text { Day } \\
\text { UCS } \\
\text { (MPa) }\end{array}$} \\
\hline & $\begin{array}{l}\text { Cement } \\
\left(\mathrm{kg} / \mathrm{m}^{3}\right)\end{array}$ & $\begin{array}{c}\text { Fly } \\
\text { Ash } \\
\left(\mathrm{kg} / \mathrm{m}^{3}\right)\end{array}$ & $\begin{array}{c}\text { Sand } \\
\left(\mathrm{kg} / \mathrm{m}^{3}\right)\end{array}$ & $\begin{array}{c}\text { Scrap } \\
\text { Tire } \\
\left(\mathrm{kg} / \mathrm{m}^{3}\right)\end{array}$ & $\begin{array}{c}\text { Water } \\
\left(\mathrm{kg} / \mathrm{m}^{3}\right)\end{array}$ & & & & \\
\hline $30 / 360 / 0.0$ & 29 & 351 & 1298 & 0 & 360 & 285 & 0.077 & 0.95 & 1.04 \\
\hline $60 / 0 / 0.0$ & 51 & 0 & 1505 & 0 & 416 & 205 & 1.00 & 8.21 & 0.11 \\
\hline $60 / 180 / 0.0$ & 60 & 180 & 1507 & 0 & 349 & 255 & 0.25 & 1.45 & 0.51 \\
\hline $60 / 180 / 0.17$ & 54 & 161 & 887 & 148 & 316 & 230 & 0.25 & 1.47 & 0.20 \\
\hline $60 / 360 / 0.0$ & 66 & 397 & 1374 & 0 & 291 & 255 & 0.14 & 0.63 & 2.19 \\
\hline $60 / 360 / 0.17$ & 60 & 357 & 887 & 143 & 314 & 255 & 0.14 & 0.75 & 0.98 \\
\hline $90 / 180 / 0.17$ & 84 & 169 & 903 & 146 & 327 & 255 & 0.33 & 1.29 & 0.42 \\
\hline 90/180/0.17 & 96 & 383 & 863 & 144 & 306 & 230 & 0.20 & 0.64 & 2.05 \\
\hline $120 / 0 / 0.0$ & 114 & 0 & 1567 & 0 & 367 & 290 & 1.00 & 3.22 & 0.84 \\
\hline $120 / 0 / 0.17$ & 88 & 0 & 792 & 139 & 308 & 200 & 1.00 & 3.48 & 0.13 \\
\hline $120 / 0 / 0.25$ & 81 & 0 & 644 & 169 & 316 & 195 & 1.00 & 3.88 & 0.07 \\
\hline $120 / 0 / 1.0$ & 68 & 0 & 259 & 270 & 224 & 100 & 1.00 & 3.31 & 0.02 \\
\hline $120 / 180 / 0.17$ & 113 & 169 & 908 & 152 & 346 & 220 & 0.40 & 1.23 & 0.64 \\
\hline $120 / 180 / 0.25$ & 104 & 156 & 730 & 182 & 335 & 205 & 0.40 & 1.29 & 0.43 \\
\hline $120 / 360 / 0.0$ & 135 & 406 & 1338 & 0 & 281 & 275 & 0.25 & 0.52 & 4.75 \\
\hline $120 / 360 / 0.25$ & 115 & 344 & 692 & 172 & 336 & 240 & 0.25 & 0.73 & 1.53 \\
\hline $120 / 360 / 1.0$ & 112 & 337 & 276 & 280 & 397 & 165 & 0.25 & 0.89 & 0.41 \\
\hline $150 / 180 / 0.17$ & 141 & 169 & 836 & 141 & 387 & 300 & 0.45 & 1.25 & 0.79 \\
\hline $150 / 180 / 0.25$ & 114 & 137 & 646 & 160 & 312 & 220 & 0.45 & 1.24 & 0.62 \\
\hline $150 / 360 / 0.25$ & 166 & 397 & 670 & 166 & 330 & 250 & 0.29 & 0.59 & 4.09 \\
\hline $150 / 360 / 1.0$ & 138 & 331 & 275 & 276 & 392 & 180 & 0.29 & 0.84 & 0.60 \\
\hline $180 / 0 / 0.0$ & 188 & 0 & 1529 & 0 & 330 & 255 & 1.00 & 1.76 & 2.65 \\
\hline $180 / 0 / 0.17$ & 139 & 0 & 833 & 139 & 336 & 215 & 1.00 & 2.41 & 0.29 \\
\hline $180 / 60 / 0.17$ & 187 & 62 & 917 & 150 & 355 & 195 & 0.75 & 1.42 & 1.09 \\
\hline $180 / 60 / 0.25$ & 129 & 43 & 642 & 161 & 355 & 220 & 0.75 & 2.07 & 0.05 \\
\hline $180 / 180 / 0.17$ & 218 & 218 & 884 & 146 & 324 & 230 & 0.50 & 0.74 & 3.79 \\
\hline $180 / 180 / 1.0$ & 124 & 124 & 258 & 259 & 350 & 150 & 0.50 & 1.41 & 0.13 \\
\hline
\end{tabular}

*defines the design proportions of the mixture by weight of cement per $\mathrm{m}^{3} /$ weight of

fly ash per $\mathrm{m}^{3} /$ ratio of weights of scrap tire to sand

†cement to cementitious materials ratio, by weight

${ }^{\ddagger}$ water to cementitious materials ratio, by weight

\section{Early Age Strength Gain}

The early age strength gain of CLSMs is important when used for backfilling trenches around utility pipes buried under roadways since the strength will dictate when the CLSM can be paved over and the road can be reopened to traffic. In this investigation, the early age strength gain was measured by penetration resistance using a concrete initial set penetrometer with either $6.3 \mathrm{~mm}$ or $25.4 \mathrm{~mm}$ diameter and a penetration depth of $6.3 \mathrm{~mm}$. The penetration resistance sample had a surface area of $225 \mathrm{~mm} \times 325 \mathrm{~mm}$ and a depth of $75 \mathrm{~mm}$. Measurements were taken after one hour and at 30 minute intervals thereafter for 12 hours or until a penetration resistance of $300 \mathrm{kPa}$ was achieved. 


\section{Compression Tests}

Compression samples were cast in plastic cylinder molds with 2:1 length to diameter ratios. 24 hours after casting, the cylinders were placed in a $100 \%$ relative humidity curing room until the day of testing, at which time they were stripped, capped, and tested. The ends of the specimens were cleaned and leveled using a wire brush and capped with plaster of paris per ASTM C 617. Compressive strength tests were conducted 3, 7, and 28 days (and occasionally 14 days) after casting.

\section{RESULTS}

\section{Air Content}

Air content not only affects the unit weight of the CLSM, but it strongly influences the compressive strength; higher air contents lead to significantly lower compressive strengths. Due to the long and thin nature of scrap tire buffings, considerable volume of air was entrapped in the mixtures. The amount of entrapped air was observed to be dependent on the relative volume of scrap tire to that of cementitious materials as shown in Figure 3. Mixtures with low volumes of cement paste (cementitious materials and water) did not fill the voids between and around the scrap tire buffings, so when the volume of scrap tire to the volume of the cementitious materials is large, the entrapped air content increases. The air content may also be influenced by the total amount of scrap tire buffings and not just the ratio of scrap tire to cementitious materials; however, a strong correlation was not observed from the data.

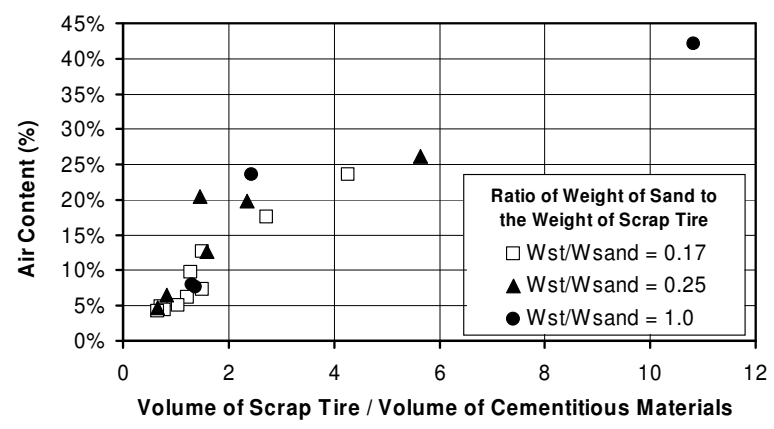

FIG. 3. Air Content as a Function of Scrap Tire Content

\section{Flow and Control of Bleeding}

One challenge with low cement and fly ash content flowable fills is being able to obtain high flow with the mixture without causing excessive bleeding. To control bleeding, a minimum amount of very fine particles is required in the mixture. Cement and fly ash serve as the fine particle constituent in CLSMs. Increasing the cement and fly ash contents also increases the compressive strength, so a balance between reduction of bleeding with high flow and excessive strength must be maintained. In this investigation, a flow of at least $200 \mathrm{~mm}$ was desirable, however, if excessive 
separation of water was occurring, no more water was added to the mixture, and the resulting flow would be less than $200 \mathrm{~mm}$.

For batches of CLSM with the highest scrap tire content $(* / * / 1.0)$, the target flow of $200 \mathrm{~mm}$ was not reached (see Table 1, samples 120/0/1.0, 120/360/1.0, 150/360/1.0, and 180/180/1.0), and these batches had cementitious material contents of up to 469 $\mathrm{kg} / \mathrm{m}^{3}$. In the batch with the highest scrap tire content and lowest cementitious materials content (120/0/1.0), a flow of only $100 \mathrm{~mm}$ was obtained.

In the four batches with an initial design of $120 \mathrm{~kg}$ of cement per $\mathrm{m}^{3}$ and no fly ash (120/0/* or samples $120 / 0 / 0.0,120 / 0 / 0.17,120 / 0 / 0.25$, and 120/0/1.0), the final flows declined steadily from $290 \mathrm{~mm}$ to $100 \mathrm{~mm}$ as the scrap tire content increased.

\section{Strength Development}

The short term penetration resistance (initial strength gain) appears to be negatively affected by introduction of scrap tire. As seen in Figure 4a, as the scrap tire content increases with mixtures containing nominal cement and fly ash amounts of 120 and $360 \mathrm{~kg} / \mathrm{m}^{3}$, respectively, the rate of the increase in penetration resistance is reduced significantly. Furthermore, Figure $4 \mathrm{a}$ seems to indicate that increasing scrap tire contents delays the time at which the mixture begins to harden (retards setting). Figure $4 \mathrm{~b}$ shows the UCS relative to its 28 day UCS for 3 to 28 days of age; this figure indicates the scrap tire may retard the strength gain around three days, but by 7 days all mixes are gaining strength at the same relative rate.

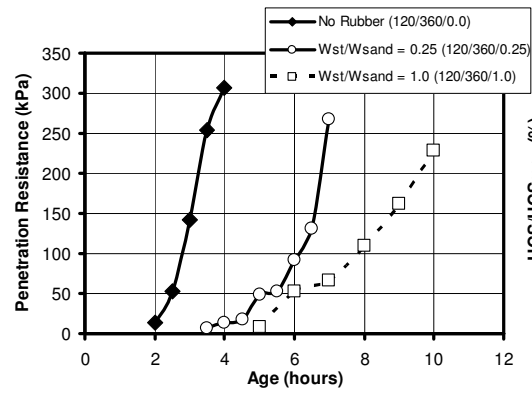

a) Short Term Penetration Resistance

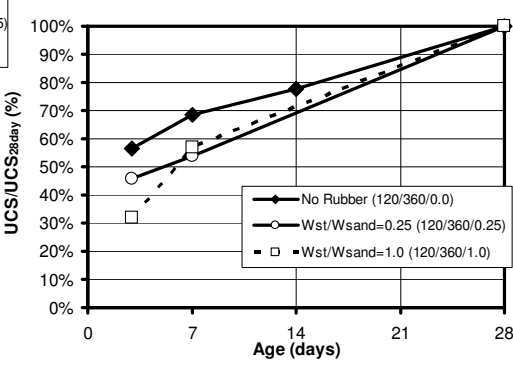

b) Longer Term UCS

FIG. 4. Effect of Rubber Content on Strength Development

\section{Long Term Unconfined Compressive Strengths (UCS)}

Prediction of long term strengths of CLSMs which incorporate scrap tire is complicated since the decrease in strength with increasing rubber content is not only due to the replacement of sand with the softer rubber but also several other factors associated with the use of rubber. Figure 5a shows a significant decrease in the unconfined compressive strength (UCS) as the scrap tire content increases; however, there is significant scatter in the results depending on the mixture proportions. Increased air content, which is a function of the ratio of the cementitious material to 
the scrap tire rubber, also decreases the UCS. By examining the decrease in compressive strength as a function of the combined volume of scrap tire and air, as shown in Figure 5b, the scatter in the data decreases. Furthermore, an increase in water demand with the increase in scrap tire rubber increases the water-to-cement ratio (or water-to-cementitious materials ratio) will also decrease the compressive strength.

The decrease in strength associated with the use of scrap tire can allow for the use of higher cement contents without increasing the UCS so much that the CLSM becomes non-excavatable. Advantages of being able to increase the cement content (or fly ash content) include easier quality control, reduction in bleeding, and greater flow. Figure 6 shows how virtually identical UCS are reached with and without the inclusion of rubber despite the nearly doubling of the cement content with the batches with rubber over a wide range of fly ash contents.

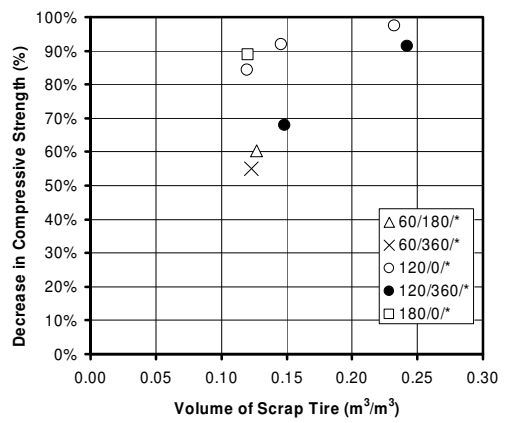

a) Not Including Air

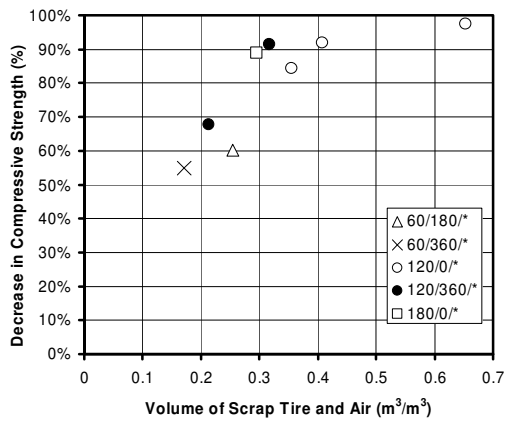

b) Including Air

FIG. 5. Relative Decrease in UCS Resulting from Incorporation of Scrap Tire

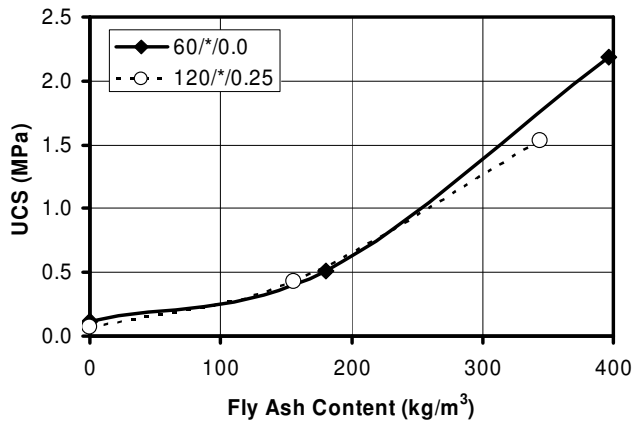

FIG. 6. Similar UCSs in CLSMs with Different Cement and Scrap Tire Contents 


\section{CONCLUSIONS}

This experimental investigation examined the use of recycled scrap tire buffings in controlled low strength materials as a means to limit the ultimate strength gain. It was shown that scrap tire buffings:

- can be used in CLSM mixtures with suitable flows, workability, and strength.

- significantly reduce the long-term unconfined compressive strength of CLSMs.

- entraps as much as $40 \%$ of air in CLSM mixtures which further reduce the strength, and this additional entrapped air must be accounted for in the mixture proportions and when predicting strengths.

o will reduce workability and increase bleeding in CLSM mixtures, but these can be overcome by increasing the amounts of cementitious materials, and the increase in strength due to the higher cementitious contents will be more than compensated by the inclusion of the scrap tire rubber.

- can help obtain equivalent UCSs in CLSMs containing different cement contents; a doubling of the cement content was compensated by increasing the weight ratio of scrap tire to sand from 0.0 to 0.25 .

\section{ACKNOWLEDGMENTS}

The work reported was sponsored in part by the Department of the Navy, Office of Naval Research, under Award \#N00014-04-1-0436.

\section{REFERENCES}

ACI Committee 229 (1999). "Controlled Low-strength Material (CLSM) (ACI 229R99)," American Concrete Institute.

Pierce, C.E. and Blackwell, M.C. (2003). "Potential of Scrap Tire Rubber as Lightweight Aggregate in Flowable Fill," Waste Management, V. 23, No. 3, pp. 197-208.

Pierce, C.E.; Tripathi, H.; Brown, T.W. (2003). "Cement Kiln Dust in Controlled Low-strength Materials," ACI Materials J., V. 100, No. 6, pp. 455-462.

Rubber Manufacturers Association (2006). "Scrap Tire Markets in the United States, 2005 Edition," http://www.rma.org/scrap tires/, accessed Oct. 20, 2007, 90 pp.

Tikalsky, P.J.; Gaffney, M.; Regan, R.W. (2000). "Properties of Controlled LowStrength Material Containing Foundry Sand," ACI Materials J., V. 97, No. 6, pp. 698-702.

Tikalsky, P.J.; Smith, E.; Regan, R.W. (1998). "Proportioning Spent Casting Sand in Controlled Low-Strength Materials," ACI Materials J., V. 95, No. 6, pp. 740-746. 